\title{
Undetected intravascular injection during an ultrasound-guided axillary block
}

\author{
C. Mauricio Forero, MD - Claudia P. Gomez Lora, MD • \\ Darius Bayegan, MSc
}

Received: 23 July 2012/ Accepted: 4 December 2012/Published online: 14 December 2012

(C) Canadian Anesthesiologists' Society 2012

\section{To the Editor,}

There is evidence that the use of ultrasound-guided regional anesthesia increases the efficacy of peripheral nerve blocks and improves safety while allowing administration of lower volumes of local anesthetics. ${ }^{1}$ Onset of the block is also faster, possibly because of visualization of the target nerve in real time and injection of local anesthetic closer to the nerve structures. ${ }^{2,3}$ It is logical to hypothesize that these advantages may reduce complications such as nerve injury and local anesthesia systemic toxicity (LAST). We report a case of LAST while performing an ultrasound-guided axillary block that was initially diagnosed by the presence of symptoms of local anesthetic toxicity. The patient provided consent for the publication of this case report.

A 63-yr-old woman, American Society of Anesthesiologists' physical status III, presented for a partial amputation of her right middle finger. An axillary block was recommended to her as an appropriate procedure. In the block room, standard monitoring was established, oxygen was applied by nasal prongs at $3 \mathrm{~L} \cdot \mathrm{min}^{-1}$, and sedation was given with midazolam $1 \mathrm{mg} i v$. A $12 \mathrm{MHz}$ linear ultrasound transducer (GE LOGIQ e, Wauwatosa, WI, USA) was placed at the deltopectoral groove. Next, the cross section of the axillary artery and the nerves surrounding it were identified. Under sterile conditions, $1 \%$ lidocaine $3 \mathrm{~mL}$ was applied to the skin and subcutaneous tissue. Using in-plane visualization, a $5-\mathrm{cm} \quad 21 \mathrm{G}$

C. M. Forero, MD - D. Bayegan, MSc

McMaster University, Hamilton, ON, Canada

C. P. Gomez Lora, MD ( $\square)$

University of Ottawa, Ottawa, ON, Canada
EchoStim ${ }^{\circledR}$ needle (Hakko ${ }^{\circledR}$ Medical, Japan) connected to a nerve stimulator was directed to the six o'clock position of the artery. After confirmation with neurostimulation (wrist extension that disappeared at $0.3 \mathrm{~mA}$ ) and negative aspiration, $5 \%$ dextrose $2 \mathrm{~mL}$ was injected and showed adequate spread around the radial nerve. After negative blood aspiration every $5 \mathrm{~mL}, 2 \%$ lidocaine was injected slowly with appropriate visualization of the spread of the injectate. When a volume of $13 \mathrm{~mL}$ was reached, the patient complained of numbness in her lips, a metallic taste in her mouth, and a sensation of fainting. At that point, the injection was interrupted, $100 \%$ oxygen via an $\mathrm{Ambu}^{\circledR}$ face mask was given, and midazolam $2 \mathrm{mg} i v$ was administered. The symptoms resolved after one minute, and the patient was transferred to the operating room where the scheduled procedure was completed. A tourniquet was used and an additional $2 \%$ lidocaine $3 \mathrm{~mL}$ was needed in the interdigital area. The patient was transferred to the recovery room hemodynamically stable.

After surgery, the ultrasound video was reviewed in detail. In the analysis (Figure, Panel A), the needle appeared to be posterolateral to the axillary artery; however, upon closer inspection, the needle tip could be seen as indenting a small anechoic structure posterior to the artery. In the next frame and just before the appearance of LAST symptoms (Figure, Panel B), local anesthetic spread could be seen as a hypoechoic image posterior to the artery. A portion of local anesthetic was likely deposited into a small vessel characterized by the anechoic structure (Figure, Panel A), accounting for the patient's symptoms. Intravascular injection occurred in spite of real-time visualization of the spread of the local anesthetic and absence of blood after needle aspiration. In this instance, enhancement artifacts posterior to the axillary artery ${ }^{4}$ may have been a confounding factor that limited visualization of the needle tip. 


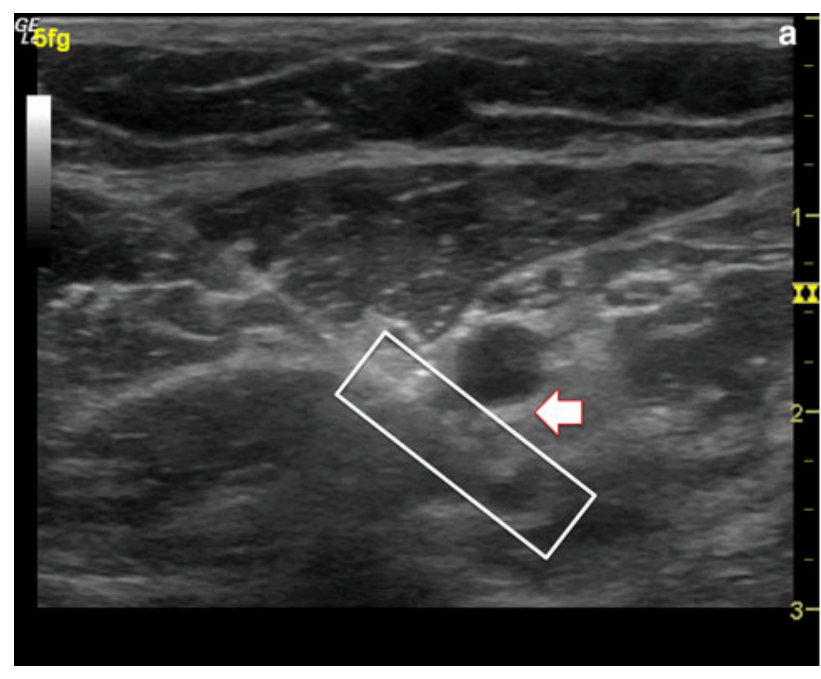

Figure Panel A) Image taken with a $12 \mathrm{MHz}$ linear ultrasound probe, cephalocaudal orientation at the deltopectoral groove. The tip of the needle can be seen at the six o'clock position of the artery. The needle tip penetrates a hypoechoic structure (white rectangle) hidden by the enhancement artifact (arrow). Panel B) Immediate sequence after

This case shows that all intravascular injections may not be identified despite the advantages of ultrasound combined with absence of blood after needle aspiration and administration of the procedure by an experienced practitioner. Incremental slow injection of small volumes of local anesthetic with appropriate clinical evaluation of the patient may remain the best strategy to prevent severe cases of LAST.

Authors' disclosure statement The authors did not receive funding to support the submitted work. They have no non-financial, commercial, proprietary, or financial interest in the products or companies described in the manuscript.

\section{Competing interests None declared.}

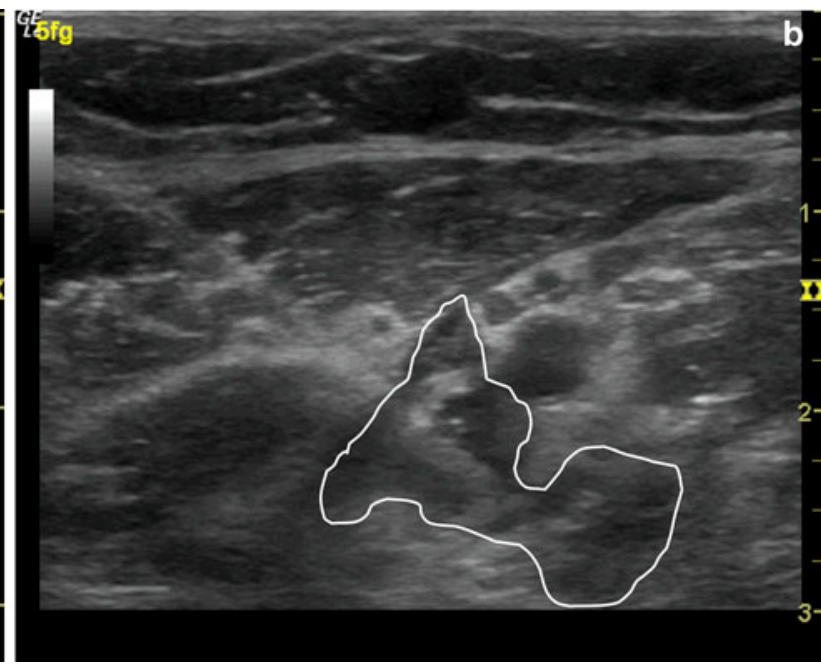

Panel A, taken before appearance of toxic symptoms with an administered volume of approximately $13 \mathrm{~mL}$ of lidocaine. Adequate spread of local anesthetic (outlined by white line) is seen posterior to the axillary artery

\section{References}

1. Neal JM, Bernards CM, Butterworth JF 4th, et al. ASRA practice advisory on local anesthetic systemic toxicity. Reg Anesth Pain Med 2010; 35: 152-61.

2. Marhofer P, Schrogendorfer K, Koinig H, Kapral S, Weinstabl C, Mayer $N$. Ultrasonographic guidance improves sensory block and onset time of three-in-one blocks. Anesth Analg 1997; 85: 854-7.

3. Liu SS, Ngeow J, John RS. Evidence Basis for ultrasound-guided block characteristics: onset, quality and duration. Reg Anesth Pain Med 2010; 35(2 Suppl): S26-35.

4. Sites BD, Brull R, Chan VW, et al. Artifacts and pitfall errors associated with ultrasound-guided regional anesthesia. Part II: a pictorial approach to understanding and avoidance. Reg Anesth Pain Med 2007; 32: 419-33. 